\title{
KOMUNITAS BURUNG PADA PERKEBUNAN KELAPA SAWIT RAKYAT DI KABUPATEN KUANTAN SINGINGI
}

\author{
Seprido \\ Universitas Islam Kuantan Singingi \\ email: sepridhopiliang@ymail.com
}

\begin{abstract}
ABSTRAK: Penelitian tentang komunitas burung pada perkebunan kelapa sawit rakyat di Kuantan Singingi ini telah dilaksanakan dari bulan Januari-Juli 2020 di beberapa perkebunan kelapa sawit rakyat. Metode yang digunakan dalam ini adalah survey langsung ke lapangan dengan pengamatan dan pengambilan data dengan menggunakan teknik point count. data jenis dan individu ditampilkan dalam bentuk tabel, dan dianalisa indek keanekaragaman jenis dan indeks kemerataannya. Dari pelaksanaan penelitian yang telah dilakukan teramati sebanyak 521 individu burung di perkebunan kelapa sawit rakyat dan termasuk kedalam 30 jenis burung. Terdapat satu jenis yang berstatus NT dan 29 berstatus LC menurut IUCN Redlist. Jenis burung yang mendominasi adalah Streptopelia chinensis dan Geopilia striata. Nilai indeks keanekaragaman Shannon Wienner sebesar 0.27; Indeks menhinick 1.85; indeks margaleft 4.48 dan evenness 0.80 .
\end{abstract}

Kata Kunci: Burung, Oil Palm, Kuantan Singingi, Komunitas

ABSTRACT: Research on bird communities in smallholder oil palm plantations in Kuantan Singingi has been carried out from January-July 2020 in several smallholder oil palm plantations. The method used in this is a direct survey to the field with observation and data collection using the point count technique. Species and individual data are presented in tabular form, and the index of species diversity and evenness index is analyzed. From the implementation of the research that has been done, 521 individual birds were observed in smallholder oil palm plantations and included in the 30 species of birds. There is one species with NT status and 29 with LC status according to the IUCN Redlist. The dominant bird species are Streptopelia chinensis and Geopilia striata. Shannon Wienner diversity index value of 0.27; Menhinick Index 1.85; margaleft index 4.48 and evenness 0.80 .

Keywords: Bird, Oil Palm, Kuantan Singingi, Community

\section{PENDAHULUAN}

Kabupaten Kuantan

perkebunan kelapa sawit merupakan komoditi perkebunan yang paling utama diusahkaan. Menurut laporan Statistik kelapa sawit dari tahun 2017-2019, di Kabupaten Kuantan Singingi tercatat luasan perkebunan kelapa sawit menapai 89.397 ha. Ditambahkan oleh (Seprido, 2018) bahwa Kelapa sawit ini merupakan komoditi perkebunan yang dominan di usahakan baik pada skala perkebunan besar swasta maupun perkebunan rakyat.
Data luasan perkebunan kelapa sawit rakyat di Kuantan Singingi pada tahun 2016 mimiliki luasan Tanaman Belum menghasilkan sebesar 10.935ha; Tanaman Menghasilkan sebesar 61.131 ha; tanaman tidak menghasilkan sebesar 73.246 ha. Sehingga total perkebunan kelapa sawit rakyat pada tahun 2015 ini di Kuantan Singingi seluas 73.246 ha dengan produksi 165.931 Ton dan Produktivitas sebesar 2.714 dan dimiliki oleh 42.303 orang (Annonymous, 2016). 
Dengan luasan perkebunan kelapa sawit rakyat ini memungkinkan juga menjadi tempat berdiam dan hidup banyak hewan. Salah satunya adalah burung.

Beberapa penelitian tentang burung diperkebunan kelapa sawit telah ditemukan sebanyak 43 jenis burung di perkebunan kelapa sawit PT. Andalas Wahana Berjaya Kabupaten Dharmasraya, Sumatera Barat (Ruswenti, Novarino, \& Rizaldi, 2014) kemudian sebanyak 85 jenis burung dari 567 individu burung di Taman Wisata Alam Seblat Bengkulu Utara (Suanto \& Mulyani, 2017), dan sebanyak 12 jenis burung dari 27 individu burung di perkebunan kelapa sawit di Pondok Pesantren Hasanatul Barokah Rokan Hulu (Saputra, Purnama, \& Lubis, 2015). Dan juga tercatat sebanyak 300 jenis di agroforest Sumatera selama 9 tahun terakhir (2002-2011). Jumlah ini mencakup 167 jenis ditemukan pada agroforest karet di Bungo Jambi, 103 jenis ditemukan pada agroforest kopi di Sumber Jaya Lampung, 146 jenis di di kawasan Sibulan Bulan Batang Toru Sumatera Utaradan 142 jenis di Kawasan Agroforest Simalungun (Ayat, 2011). Dan sebanyak 70 jenis burung teramati di areal pekebunan kelapa sawitPT. Kencana Sait Indonesia (Seprido. 2013).

Sedangkan untuk kawasan perkebunan kelapa sawit khususnya perkebunan kelapa sawit rakyat di Kabupaten Kuantan Singingi masih belum ada dijumpai.

Berdasarkan uraian diatas maka perlu adanya penyelidikan tentang komunitas burung yang hidup pada perkebuan kelapa sawit rakyat di Kabupaten Kuantan Singini.

\section{METODE PENELITIAN}

Penelitian ini dilaksanakan di kawasan perkebunan kelapa sawit rakyat di 3 kecamatan di kabupaten Kuantan Singingi. Stasiun 1 diletakkan di perkebunan kelapa sawit rakyat di kec Kuantan Mudik dengan luasan perkebunan sekitar 24 ha. Stasiun 2 diletakkan di perkebunan kelapa sawit rakyat di kecamatan Sentajo Raya dengan luasan lahan pada stasiun ini adalah 18 ha. Sedangkan stasiun 3 diletakkan di perkebunan kelapa sawit rakyat di kecamatan Singingi dengan luas 53 ha. Secara keseluruhan luas areal penelitian ini adalah 95 ha dan keseluruhan populasi kelapa sawitnya tergolong tanaman menghasilkan.

Penelitian ini dilakukan selama 6 bulan pengamatan dari bulan Januari hingga Juli 2020 dengan menggunakan alat berupa binoculer dan buku identifikasi Burung MacKinoon (2010), kamera Cannon, kompas, meteran, thally sheet, dan alat tulis. Objek penelitian ini adalah burung yang terdapat di dalam jalur pengamatan.

Penelitian ini menggunakan metode survey dan observasi lapangan. Untuk pengamatan jenis dan individu burung dilapangan menggunakan teknik Point Count (Bibby, Jones, \& Marsden, 2000). Data hasil pengamatan dilapangan disajikan dalam bentuk tabel dan akan dianalisa secara deskriptif.

\section{HASIL DAN PEMBAHASAN 3.1 Habitat}

Stasiun 1. adalah kawasan perkebunan kelapa sawit rakyat yang terletak di kecamatan Kuantan Mudik. Luasan perkebunan pada stasiun ini adalah sekitar 24 ha yang terletak dalam satu hamparan. Tahun tanam kelapa sawit pada stasiun ini adalah tahun 2006, 2008 dan 2009. Disekitar kawsan perkebunan ini berbatasan dengan kebun karet dan hutan sekunder.

Stasiun 2 adalah kawasan perkebunan kelapa sawit rakyat yang terletak di kecamatan Sentajo Raya. Luasan perkebunan pada stasiun ini adalah sekitar 18 ha dan juga terletak dalam satu hamparan. Tahun tanam kelapa sawit pada stasiun ini adalah tahun 2007, 2008 dan 2010. Kawasan perkebunan kelapa sawit ini berbatasan dengan hutan kebun karet dan semak belukar. 
Stasiun 3 adalah kawasan perkebunan kelapa sawit yang terletak di kecamatan singingi dengan luasan perkebunan sekitar 53 ha dan terletak dalam satu hamparan. Kawasan perkebunan ini berbatasan dengan perkebunan karet dan semak belukar.

\subsection{Komunitas Burung}

\section{Kekayaan dan keanekaragaman spesies}

Sebanyak 521 individu burung teramati di perkebunan kelapa sawit rakyat di Kuantan Singingi. Dari proses identifikasi burung yang dilakukan semuanya tergolong ke dalam 42 jenis burung, 23 family dan 9 ordo (Tabel 1).

Menurut Redlist IUCN terdapat 29 jenis berstatus LC (Least Concerned) dan 1 jenis yang tergolong kedalam NT (Neart Threathened) yaitu Prinia familiaris (International, 2018)

Setiap stasiun penelitian memiliki jumlah jenis dan komposis jenis yang tidak terlalu jauh berbeda (Tabel 1). Tidak terlalu berbedanya keanekaragaman dan kekeayan jenis masing masing pada stasiun penelitian dipengaruhi oleh komposisi vegetasi penyusun yaitu sama sama kelapa sawit. Meskipun demikian terdapat juga perbedaan jumlah jenis yaitu pada stasiun 1 dijumpai sebanyak 192 individu dan terolong kedalam 23 jenis burung, pada stasiun dua dijumpai sebanyak 160 individu burung dan tergolong kedalam 20 jenis burung dan pada stasiun 3 dijumpai sebanyak 169 jenis burung dan tergolong kedalam 24 jenis.

Adanya perbedaan jumlah jenis ini disebabkan oleh luasan perkebunan dan vegetasi penyusun di sekitar perkebunan kelapa sawit. Menurut Ueharo-Prado et al (2009) pada hutan yang mengalami gangguan akibat aktivitas manusia menunjukan penambahan individu pada hutan terganggu lebih disebabkan oleh kehadiran jenis bukan asli dan Imanuddin (2009) kehadiran areal perkebunan disekitar hutan akan memungkinkan penambahan individu yang berasal dari kebun ke hutan dan begitu juga sebaliknya.

Tabel 1. Jenis jenis burung di perkebunan kelapa sawit rakyat di kabupaten Kuantan Singingi

\begin{tabular}{|c|c|c|c|c|c|c|}
\hline \multirow[t]{2}{*}{ No } & \multirow[t]{2}{*}{ Jenis } & \multirow{2}{*}{$\begin{array}{c}\text { IUC } \\
\mathbf{N} \\
\text { Redl } \\
\text { ist }\end{array}$} & \multicolumn{3}{|c|}{ Stasiun } & \multirow{2}{*}{$\begin{array}{c}\text { Juml } \\
\text { ah }\end{array}$} \\
\hline & & & $\mathbf{1}$ & 2 & 3 & \\
\hline 1 & Spilornis cheela Latham 1790 & $\mathrm{LC}$ & $\sqrt{ }$ & - & - & 4 \\
\hline 2 & Gallus gallus Linneaus 1758 & $\mathrm{LC}$ & $\sqrt{ }$ & - & - & 8 \\
\hline 3 & Streptopelia chinensis (Scopoli, 1786) & LC & $\sqrt{ }$ & $\sqrt{ }$ & $\sqrt{ }$ & 132 \\
\hline 4 & Geopelia striata Linnaneus 1766 & $\mathrm{LC}$ & $\sqrt{ }$ & $\sqrt{ }$ & $\sqrt{ }$ & 71 \\
\hline 5 & Chalcophaps indica Linnaeus 1758 & $\mathrm{LC}$ & $\sqrt{ }$ & $\sqrt{ }$ & $\sqrt{ }$ & 21 \\
\hline 6 & Loriculus galgulus Linnaeus, `758 & $\mathrm{LC}$ & $\sqrt{ }$ & - & $\sqrt{ }$ & 5 \\
\hline 7 & Centropus sinensis Stephens, 1815 & $\mathrm{LC}$ & $\sqrt{ }$ & $\sqrt{ }$ & $\sqrt{ }$ & 19 \\
\hline 8 & Centropus bengalensis Gmelin, 1788 & $\mathrm{LC}$ & $\sqrt{ }$ & $\sqrt{ }$ & $\sqrt{ }$ & 3 \\
\hline 9 & Collocalia esculenta Linnaues 1758 & $\mathrm{LC}$ & $\sqrt{ }$ & $\sqrt{ }$ & $\sqrt{ }$ & 44 \\
\hline 10 & Buceros rhinoceros Linnaeus 1758 & VU & $\sqrt{ }$ & - & - & 2 \\
\hline 11 & Psilopogon eximius & $\mathrm{LC}$ & - & $\sqrt{ }$ & $\sqrt{ }$ & 2 \\
\hline 12 & Psilopogon haemacephalus & $\mathrm{LC}$ & $\sqrt{ }$ & - & $\sqrt{ }$ & 3 \\
\hline 13 & Blhytipicus rubiginosis Swainson 1837 & $\mathrm{LC}$ & - & $\sqrt{ }$ & - & 2 \\
\hline 14 & Pycnonotus atriceps (temminck, 1822) & $\mathrm{LC}$ & $\sqrt{ }$ & - & - & 3 \\
\hline 15 & Pycnonotus gioavier (Scopoli, 1786) & $\mathrm{LC}$ & $\sqrt{ }$ & $\sqrt{ }$ & $\sqrt{ }$ & 4 \\
\hline
\end{tabular}

Bio-Lectura: Jurnal Pendidikan Biologi, Vol 7, No 2, Oktober 2020 


\begin{tabular}{|l|l|l|l|l|l|l|}
\hline 16 & Pycnonotus aurigaster (Jardine \& Selby 1837) & LC & $\sqrt{ }$ & - & - & 29 \\
\hline 17 & Pycnonotus simplex Lesson, 1839 & LC & $\sqrt{ }$ & - & $\sqrt{ }$ & 10 \\
\hline 18 & Lanius tigrinus Drapiez, 1828 & LC & - & - & $\sqrt{ }$ & 1 \\
\hline 19 & Halcyon smyrnensis & LC & $\sqrt{ }$ & $\sqrt{ }$ & $\sqrt{ }$ & 62 \\
\hline 20 & Halcyon cyanoventris & LC & $\sqrt{ }$ & $\sqrt{ }$ & $\sqrt{ }$ & 15 \\
\hline 21 & Copsicus saularis (Linnaeus, 1758) & LC & $\sqrt{ }$ & $\sqrt{ }$ & $\sqrt{ }$ & 23 \\
\hline 22 & Prinia familiaris Horsfield, 1821 & NT & $\sqrt{ }$ & $\sqrt{ }$ & $\sqrt{ }$ & 14 \\
\hline 23 & Prinia flaviventris & LC & $\sqrt{ }$ & $\sqrt{ }$ & $\sqrt{ }$ & 3 \\
\hline 24 & Orthotomus ruficeps (Lesson, 1830) & LC & - & $\sqrt{ }$ & $\sqrt{ }$ & 3 \\
\hline 25 & Dicaeum trigonostigma (scopoli, 1776) & LC & $\sqrt{ }$ & $\sqrt{ }$ & $\sqrt{ }$ & 19 \\
\hline 26 & Anthreptes simplex (S. Muller, 1843) & LC & - & $\sqrt{ }$ & - & 2 \\
\hline 27 & Chalcoparia singalensis & LC & $\sqrt{ }$ & $\sqrt{ }$ & $\sqrt{ }$ & 2 \\
\hline 28 & Lonchura punctulata (Linnaues, 1758) & LC & $\sqrt{ }$ & $\sqrt{ }$ & $\sqrt{ }$ & 3 \\
\hline 29 & Lonchura striata & LC & $\sqrt{ }$ & $\sqrt{ }$ & $\sqrt{ }$ & 9 \\
\hline 30 & Corvus enca & LC & & & $\sqrt{ }$ & 3 \\
\hline TOTAL & & & & & 521 \\
\hline
\end{tabular}

Jumlah jenis terbanyak dijumpai pada stasiun 3 yaiutu sebanyak 24 jenis sedangkan jumlah individu terbanyak dijumpai di stasiun 1 yaitu sebanyak 192 individu. Jenis yang mendominasi secara keseluruhan adalah Streptopelia chinensis (25.34\%) kemudian diikuti oleh Geopelia striata (13.62\%) dan Halcyon smyrnensis (11.90\%). Menurut Ayat (2011) jenis Streptopelia chinensis ini merupakan jenis yang sangat umum di daerah agroforest, pemukiman, persawahan dan perkebunan.

Dominansi berdasarkan jenis, pada stasiun 1 didominasi oleh jenis Streptopelia chinnsis (33.85\%) dan diikuti oleh Geopelia striata (9.89\%) dan Collocalia esculenta (6.25\%). Pada stasiun 2 didominasi oleh

Streptopelia chinensis (20\%) dan diikuti oleh Geopelia striata $(16.88 \%)$ serta Collocalia esculenta dan Halcyon smyrnensis masin masingnya (13.13). Sedangkan pada stasiun 3 didominasi oleh Streptopelia chinensis $(20.7 i \%)$ diikuti oleh Halcyon smyrnensis (18.34\%) dan Geopelia striata $(14.79 \%)$.

Tingginya jenis jenis ini dijumpai di lokasi penelitian disebabkan oleh jenis ini merupakan jenis yang sangat umum dijumpai di areal perkebunan di Sumatra (MacKinnon et al, 2010).

Hasil analisa kekayaan, kemerataan dan keanekaragaman jenis burung dilokasi penelitian relatif cukup tinggi (Tabel 2.).

Tabel 2. Perbandingan nilai indeks kekayaan, kemerataan dan keanekaragaman jenis burung berdasarkan lokasi penelitian

\begin{tabular}{|l|l|l|l|l|}
\hline \multirow{2}{*}{ Lokasi } & \multicolumn{4}{|c|}{ Nilai } \\
\cline { 2 - 5 } & \multicolumn{1}{|c|}{ Shanon } & \multicolumn{1}{|c|}{ Menhinick } & Margaleft & Evenness \\
\hline Stasiun 1 & 0.20 & 1.66 & 4.18 & 0.06 \\
\hline Stasiun 2 & 0.27 & 1.58 & 3.75 & 0.80 \\
\hline Stasiun 3 & 0.18 & 1.85 & 4.48 & 0.57 \\
\hline
\end{tabular}

Keanekaragaman dan kekayaan jenis burung di lokasi penelitian tergolong rendah . hal ini terlihat dari nilai indeks keanekaragaman Shanon Wienner yaitu yang tertinggi pada stasiun 2 yaitu 0.27 dan begitu juga dengan nilai indeks lainnya. Rendahnya nilai indeks dilkoasi penelitin ini disebabkan oleh jenis vegetasi yang sama yaitu tanaman kelapa sawit. Menurut Novarino (2008) menyatakan bahwa salah

Bio-Lectura: Jurnal Pendidikan Biologi, Vol 7, No 2, Oktober 2020 
satu faktor yang mempengaruhi nilai indeks keanekaragaman jens adalah jenis yang menyusun vegetasi pada habitat tersebut.

Indeks kesamaan jenis dengan menggunakan indeks Jaccard pada Tabel 3.

Tabel 3. Indeks kesamaan Jaccard untuk komunitas burung berdasarkan stasiun penelitian di perkebunan kelapa sawit rakyat di Kuantan Singingi

\begin{tabular}{|l|l|l|l|}
\hline Lokasi & Stasiun 1 & Stasiun 2 & Stasiun 3 \\
\hline Stasiun 1 & & 0.39 & 0.37 \\
\hline Stasiun 2 & & & 0.37 \\
\hline Stasiun 3 & & & \\
\hline
\end{tabular}

\section{KESIMPULAN}

Dari penelitian dan pembahasan, dapat disimpulkan bahwa areal perkebunan kelapa sawit di Kuantan Singingi ditemukan sebanyak 521 individu burung dan tergolong kedalam 30 jenis dengan nilai keanekaragaman jenis Shannon Wienner tertinggi 0.27, Menhinick 1.85, Margaleft 4.48 dan Indeks Kekayaan jenis 0.80.

\section{REFERENSI}

Annonymous. (2016). Tree Crop Estate Statistic of Indonesia Palm Oil. Jakarta: Direktorat Jendral Perkebunan. Retrieved from http://ditjenbun.pertanian.go.id

Ayat, A. (2011). Burung-burung. Bogor: World Agroforestry Centre-ICRAF.

Bibby, C., Jones, M., \& Marsden, S. (2000). Teknik-Teknik Ekspedisi Lapangan Survei Burung. Bogor: Birdlife International Indonesia Programme.

International, B. (2018). Birdlife International. The IUCN Red List of Threatened Species 2018, 8235(e.T22713598A131851023). Retrieved from http://dx.doi.org/10.2305/IUCN.UK.20182.RLTS.T22713598A131851023.en\%0A Copyright:

Imanuddin. 2009. Komunitas Burung di Bawah Tajuk pada Hutan Primer dan dan Sekunderdi Taman Nasional Bukit Barisan Selatan. Tesis Sekolah terlihat komunitas burung pada tiga stasiun penelitian mempunyai tingkat kesamaan yang cukup. Nilai indeks kesamaan berkisar antara 0.37 hingga 0.39 .
PAscasarjana. Institut Pertanian Bogor. Bogor (Unpublished)

MacKinnon, J., Philips, K., dan van BAlen, B. 2010. Buku Panduan Lapangan Burung Burung di Sumatera, Jawa, Bali dan Kalimantan. Burung indonesia Bogor.

Novarino, W. 2008. Dinamika JAngka PAnjang Komunitas Burung Strata BAwh di Sipisang, Sumatera BArat. Disertasi Doktoral. Program Pascasarjana, Institut Pertanian Bogor. Bogor.

Ruswenti, E., Novarino, W., \& Rizaldi. (2014). Jenis-Jenis Burung di Perkebunan Kelapa Sawit PT . Andalas Wahana Berjaya ( Sumatera Barat Bird Species at Oil Palm Plantation of PT . Andalas Wahana Berjaya ( AWB ),. Jurnal Biologi Universitas Andalas, 3(September), 219226.

Saputra, R., Purnama, A. A., \& Lubis, R. R. (2015). Jenis-jenis burung di perkebunan kelapa sawit pondok pesantren hasanatul barokah rokan hulu. Jurnal Ilmiah Mahasiswa FKIP Prodi Biologi, 1(1). Retrieved from https://ejournal.upp.ac.id/index.php/fkipbiologi/art icle/view/357

Seprido. (2018). MODEL AGROEKOSISTEM. In Prosiding Seminar Nasional Penelitian dan Pengabdian (pp. 1-5).

Seprido. 2013. Komunitas Burung Pada Tiga Tipe Habitat di Areal Perkebunan PT. Kencana Sawit Indonesia (KSI Solok Selatan, Sumatera Barat. Thesis Program AWB ), Kabupaten Dharmasraya ,

Bio-Lectura: Jurnal Pendidikan Biologi, Vol 7, No 2, Oktober 2020 
Pascarasarjana Biologi Universitas Andalas Padang.

Suanto, E., \& Mulyani, Y. A. (2017).

Komunitas Burung Pada Tiga Habitat di

Taman Wisata Alam Seblat ( TWAS )

Bengkulu Utara , Bengkulu Berdasarkan

Penggunaan Metode Jala Kabut dan Titik

Hitung. In Komunitas Burung Pada Tiga

Tipe Habitat di Taman Wisata Alam

Seblat (TWAS) Bengkulu Utara, Bengkulu

Berdasarkan Penggunaan Metode Jala

Kabut dan Titik Hitung. Fakultas

Kehutanan Institut Pertanian Bogor.

Retrieved from

https://www.researchgate.net/publication/ $315711300 \% 0$ AKomunitas

Uehara-PradoM, Fernandes, JDo, Bello Adm,

Machado G, Santos, Aj., Vaz-deMello FZ,

Freitas AVL. 2009. Selecting terresterial

Arthropods as Indicators of Small-Scale

Disturbance : A Forst Approach in the

Brazillian Atlantic Forest. Biological

Conservation 142:1220-128. 